不搯乱犾態のシラスの動的性兵

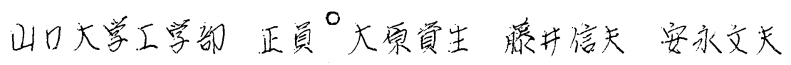

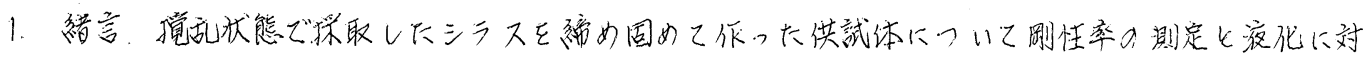

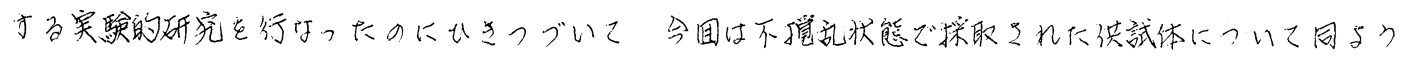
の实験を行㖪ったので光の就果を教告する。

2. 誡料不境乱試料も㹸乱三ラスと同じ都城市付近 で採取されにもので。直经约 $10 \mathrm{~cm}$ 長之2 $0 \mathrm{~cm}$ のブリ

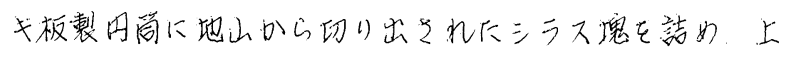
下をパラフインで密封したものである。自然含水比の 平均は2 1 . $36 \%$ ，乾燥学位重量は1.12 \% $\mathrm{cm}^{3}$ 自然间

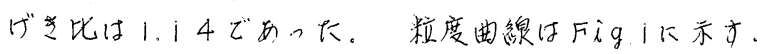

3. 实験装㯰およ《实験方法今团の实験には動的单

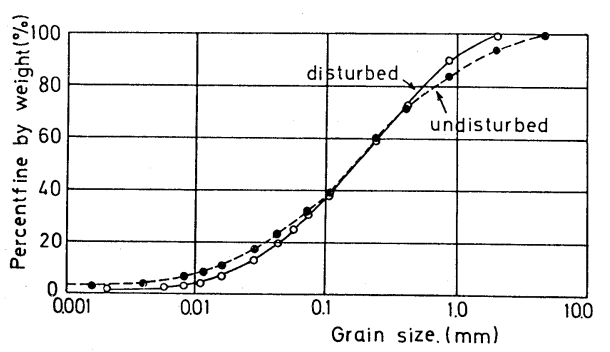

Fig. | Grain size distribution curves

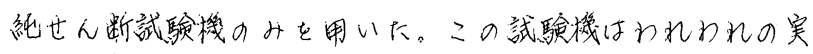

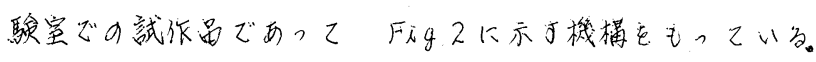

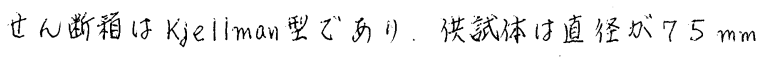
原之が20.mmの日板状であり、ゴムスリーブの中に收め

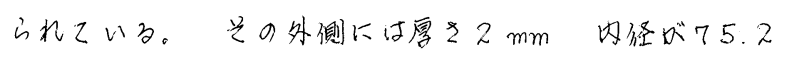
$\mathrm{mm}$ 外径が96 mmのアクリルリングが।2〜14枚つ 小重的的几K状態ではめられている。

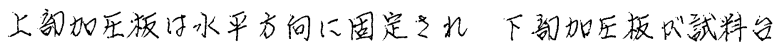

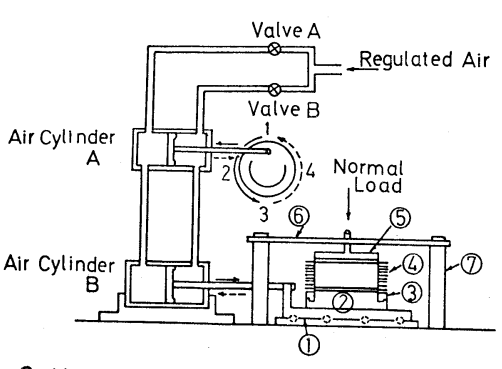

Fig. 2 Mechanism of dynamic simple shear test

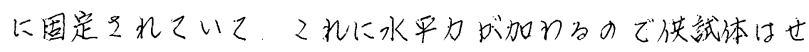

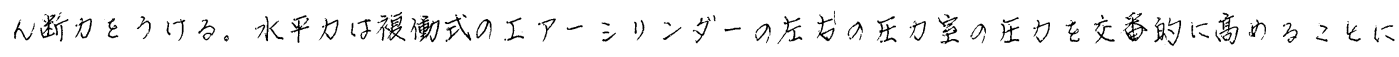

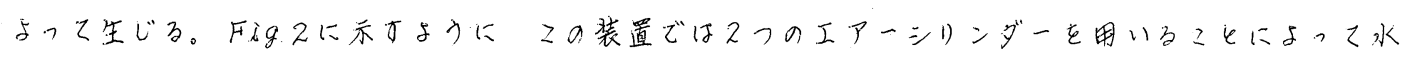

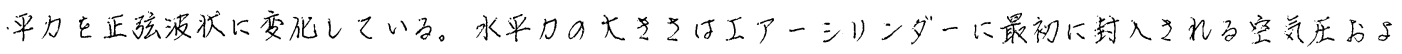

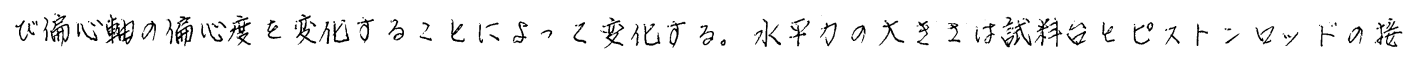

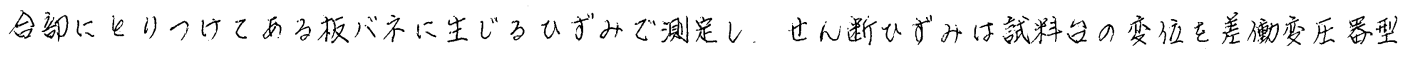

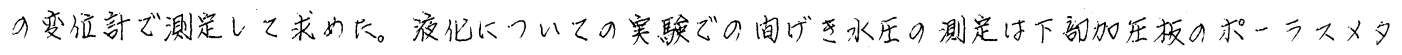

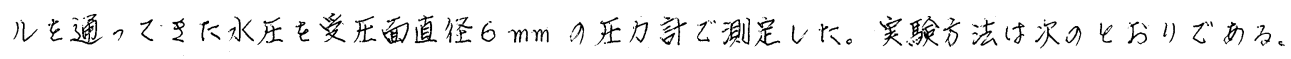

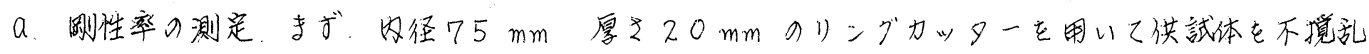

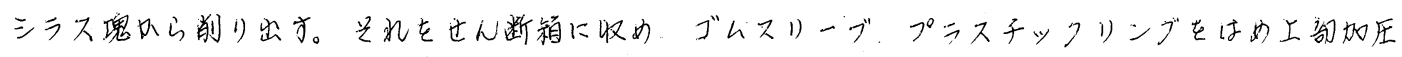

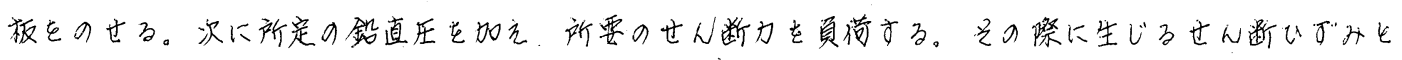

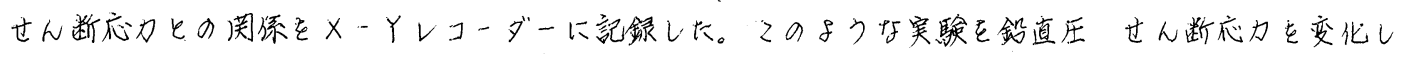
乙行坆ん长。

も、液化についての实驗、洪試体を切り出し、光れをせん断箱にセットするまではのと同じである。 


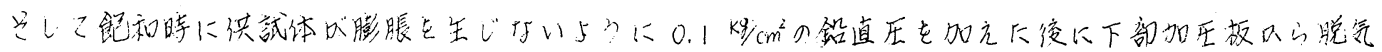

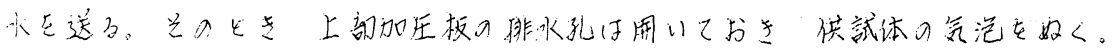

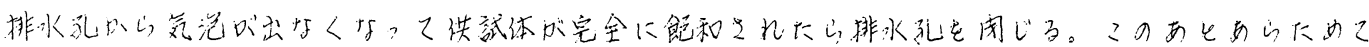

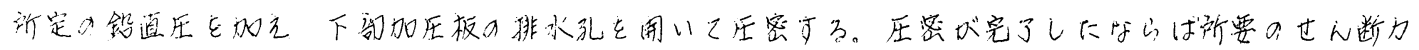

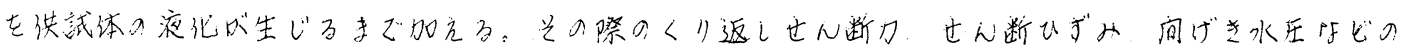

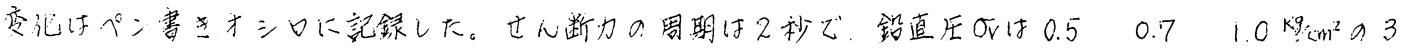
段溜に变化して实験要行打。长。

\section{4 实驗結果比光入考察}

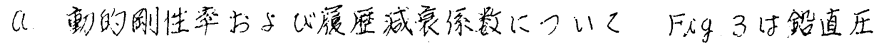

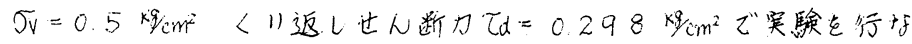

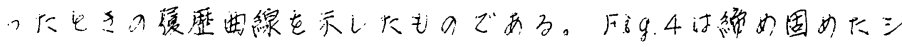

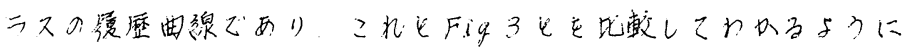

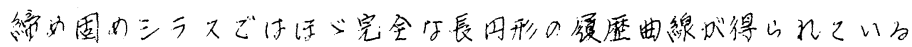

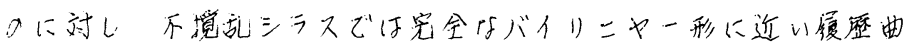

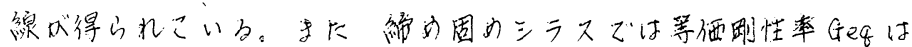

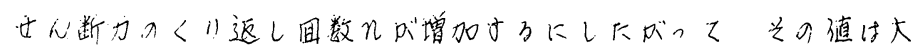

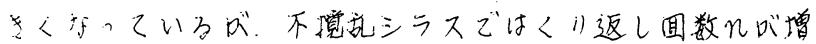

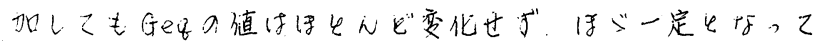

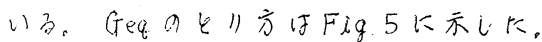

ま下绵由圈如三 ラスでは所可6に示 才。ंにGeq/SV は

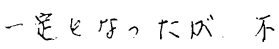
摚乱シラマでは兰北

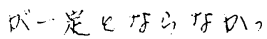

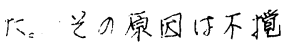
乱シラスではめる䄇

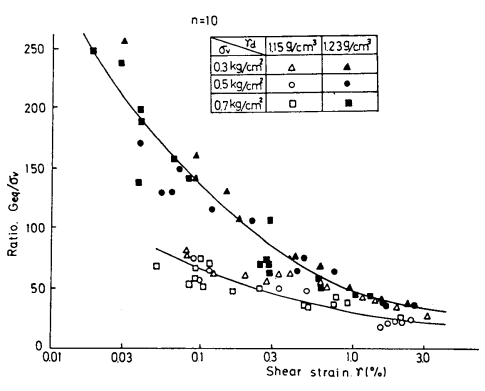
Fig. 6 Relationships between ratio Gea/or and strain 度力粒子间の結合力をも つ势门光力下内压密 降优荷重在毛っていると 同じ状態に得っているた 为考元的视。

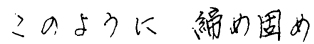
シラスと不㑽乱シラスと で付性质が相当に異际る

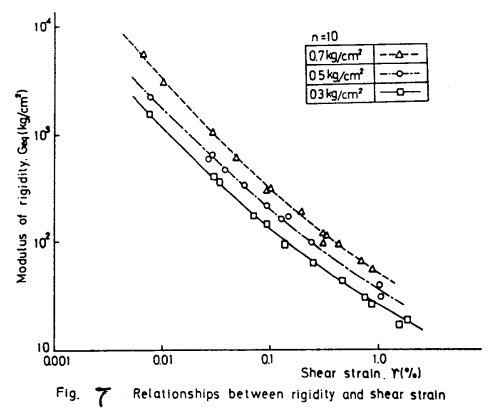

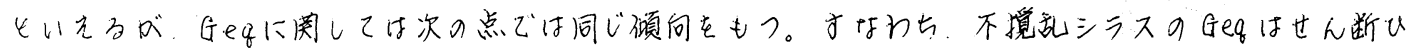

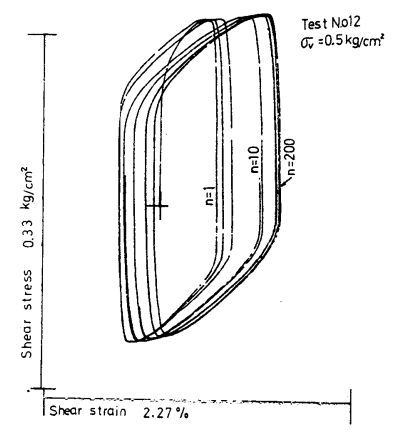

Fig.3 Hysteresis curve (Undisturbed sample)

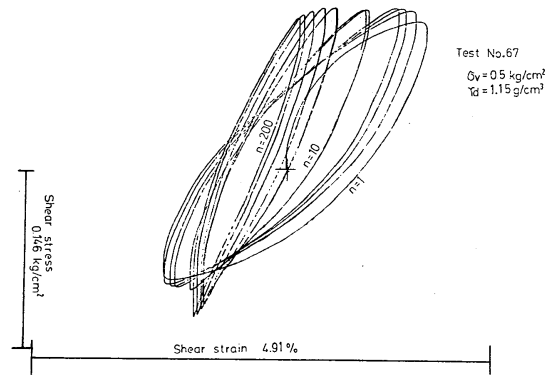

Fig. 4 Hysteresis curve (Compacted sample)

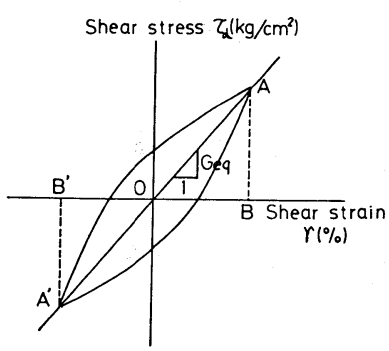

Fig. 5 Equivalent hysteretic stress-strain properties 


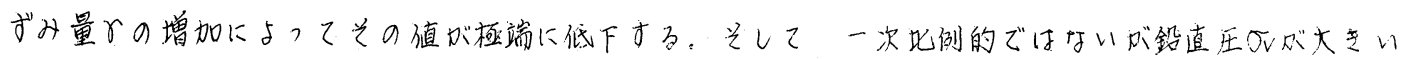

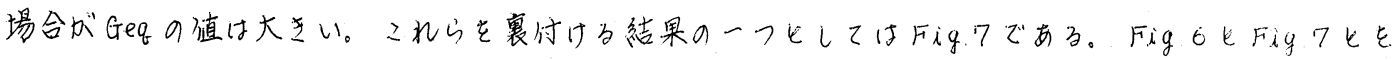

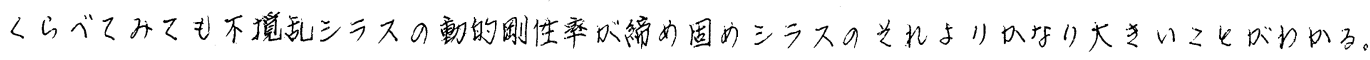

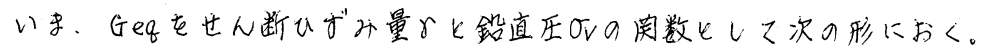

$$
G \text { eq }=c\left(\sigma_{v}\right)^{m} / r^{n}
$$

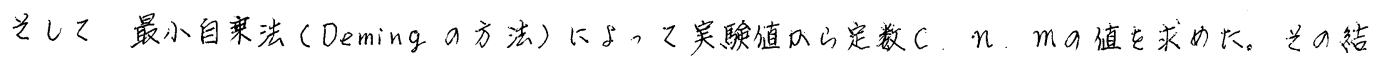
果が右の表である。にア゙し，之の值けれ=100 と去G Geqを用いて求められたもので西り世人

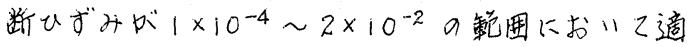
用できるものと考元る。

\begin{tabular}{|c|c|c|c|c|}
\hline \multicolumn{2}{|l|}{ 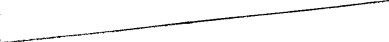 } & $c$ & $n$ & $m$ \\
\hline \multirow{2}{*}{ 締め固めシラス } & $\gamma_{d}=1.15 \mathrm{~g} / \mathrm{m}^{3}$ & 10.27 & 0.25 & 1.02 \\
\hline & $\gamma_{d}=1.23 \mathrm{~g} / \mathrm{cm}^{3}$ & 6.11 & 0.45 & 1.06 \\
\hline 不壋乱三ラ又 & $\gamma_{d}=1.12 \mathrm{~g} / \mathrm{m}^{3}$ & 1.90 & 0.82 & 1.15 \\
\hline
\end{tabular}

次に等硒履歴减衰定数入凡についてであるが、?の值はFig 5

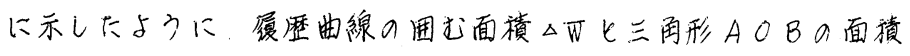
四との比をと, て次の(て)式によって求め长。す柿りち

$$
\lambda_{R}=\frac{1}{4 \pi} \frac{\Delta W}{W}
$$

単の結果の例をFig.8に示した。

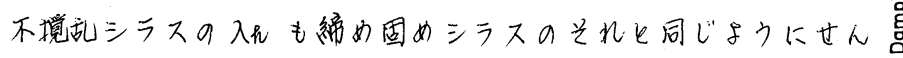
断力のくり返し国数の增加によって入れの值は減少している。

しฌし、せん断ひずみ量ての增加によってはあまり变化してい

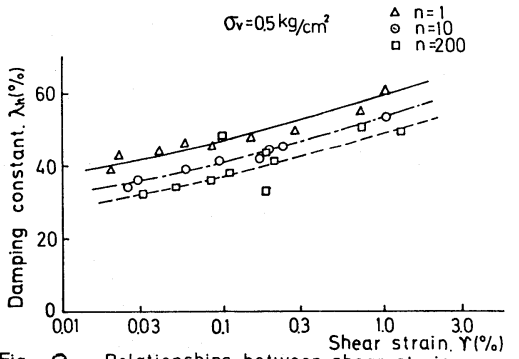

Fig. 8 Relationships between Shear strain.

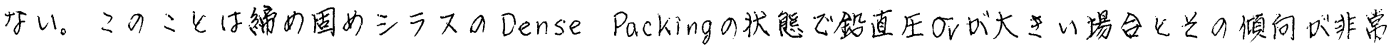
によく似ているといえる。ま下，不壋乱シラスの入れは締め固めシラスの光れの约々倍の数值を示し ているが、これは雨者の履歴曲缐の形の相異によるものである。

b. シラスの液化。Fig.9は不摚乱シラスの实駼記録 の例である。 それらの例からクか子ように供試体にく

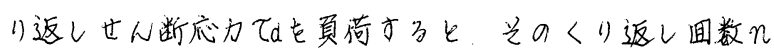
が增加するにつれて供武体中の间げ水压Uが次矛に上 畀しFig.9に示した例ではn=13〜14 付近から世山断 变位が增大しはじめ、年時点で初期夜化がお2つてい るこヒがクかる。光てで初期底化が起るまでのせん断力

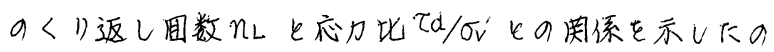

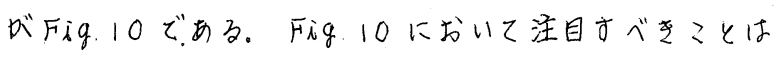
不境乱三ラスの夜化は兰れが発生するまでの世ん断忘力

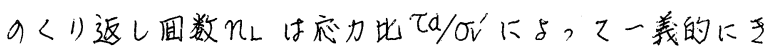
まら甲いといク点である。

2のマとが不境乱三ラスの液化と境方シラスの夜化と の大之山相異点で西子。?の相異点の原因は動的别性率 の測定結果のとンろでものべたょうに不徭乱シラスに

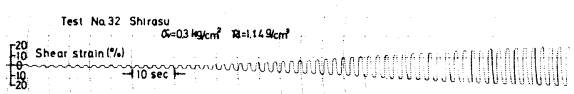

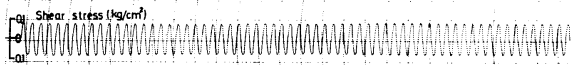

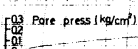

Fig. 9 Record of dynamic simple shear test

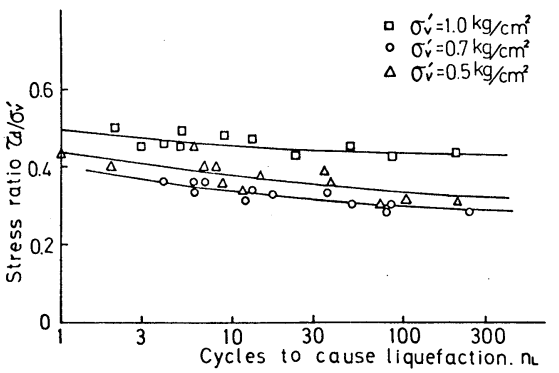

Fig. 10 Stress ratio $\tau_{d} / \sigma_{v}^{\prime}$ required to cause liquefaction 
は土粒子间にある種の結合力が存在しているてとによるものと思われる。Fig.儿は初期液犾化が生じ

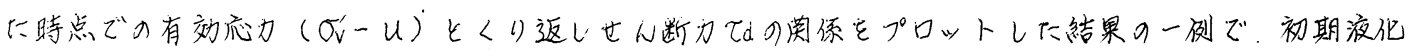

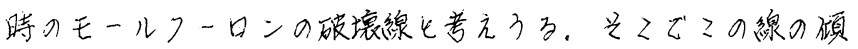

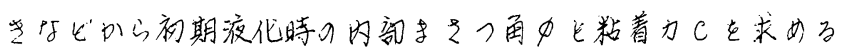

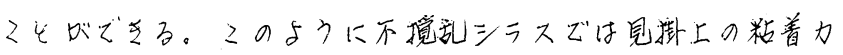

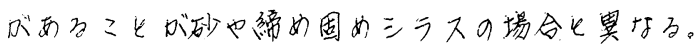

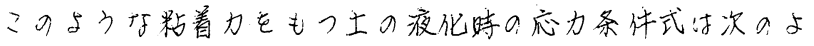
れに考方的れる。

$$
\tau_{\alpha}=c+\left(\sigma_{v}^{\prime}-u_{f}\right) \tan \phi
$$

(3)式を(4)式のうにし、雨辺を毛で除すれば。

$$
\begin{aligned}
& \tau_{d}-c=\left(\sigma_{v}^{\prime}-u_{f}\right) \tan \phi \\
& \frac{\tau_{d}-c}{\sigma_{v}^{\prime}}=\left(1-\frac{u_{f}}{\sigma_{v}^{\prime}}\right) \tan \phi
\end{aligned}
$$

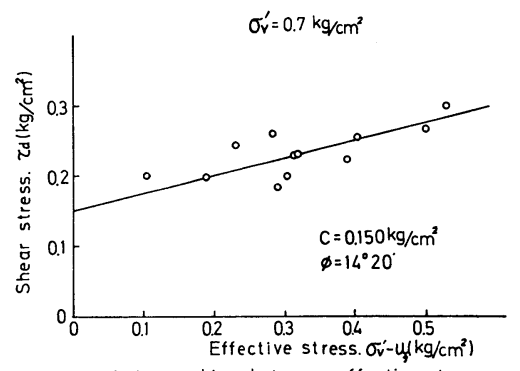
Fig. II Relationships between effective stress
and shear stress

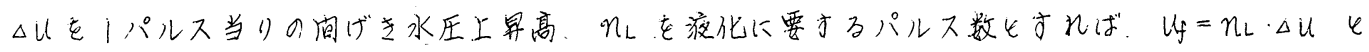
特るカで

$$
\frac{\tau_{d}-c}{\sigma_{v^{\prime}}}=\left(1-\frac{n_{i} \cdot \Delta u}{\sigma_{v}^{\prime}}\right) \tan \phi
$$

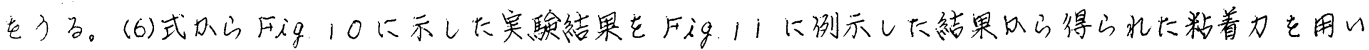

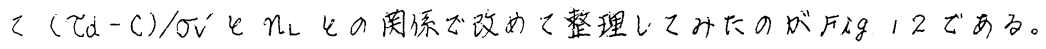

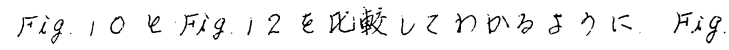
10 では宁のちがいによってろ本の線にクかれてい た結果がFig12ではほづ、本の㟫にまとまっている ンとボクかり，不境乱三ラスの液化には土粒子间の結

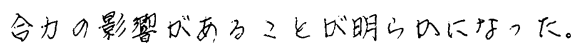

5. 結語今国行师。下不摬乱三ラスの動的性真K

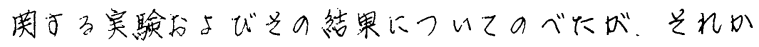

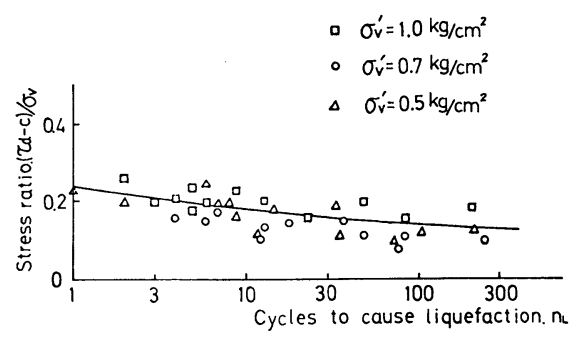

$F_{i g} 12$ Stress ratio $\left(\tau_{d}-c\right)_{\sigma v}$ required to cause liquefaction

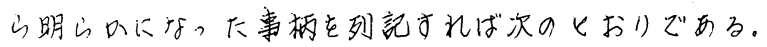

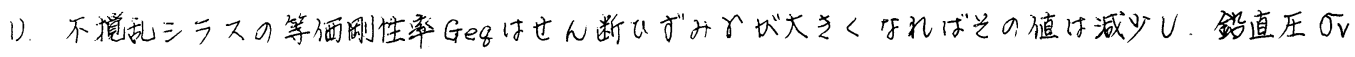
が大きく扑ば乥の值け增加する。三者の成係を示す实驗式は次のとおけである。

$$
G e q=\frac{1.90}{\gamma^{0.82}} \sigma_{v}^{1.15}
$$

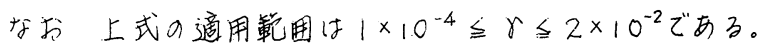

2) ま长、等酒履歷减衰定数入见はGeqとは迸の倾向を示す。

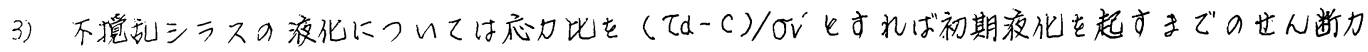

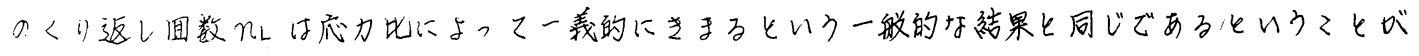
いえる。 